Boise State University

ScholarWorks

Marketing Faculty Publications and

Presentations

3-2020

\title{
Actions Speak Louder Than Words: How Characters' Effectiveness as Message Sources Depend on Their Story Experiences
}

Cristel Antonia Russell

Pepperdine University

Anne Hamby

Boise State University

Boris Chapoton

Lucien Neuwirth Cancer Institute

Véronique Régnier Denois

Lucien Neuwirth Cancer Institute 


\title{
Actions Speak Louder Than Words: Television Characters' Effectiveness as Message Sources Depends on Their Story Experiences
}

\author{
Cristel Antonia Russell \\ Graziadio School of Business \\ Pepperdine University \\ Malibu, CA, USA \\ cristelrussell@fulbrightmail.org \\ Boris Chapoton \\ Faculté de Médecine \\ Université Jean Monnet Saint-Etienne \\ Saint Priest en Jarez, France \\ boris.chapoton@univ-st-etienne.fr.
}

\author{
Anne M. Hamby \\ School of Business \\ Boise State University \\ Boise, ID, USA \\ anne.hamby@gmail.com \\ Véronique Régnier Denois \\ Laboratoire HESPER EA 7425 \\ Institut de Cancérologie de la Loire \\ Saint Priest en Jarez, France \\ veronique.regnier@univ-st-etienne.fr.
}

\begin{abstract}
A television (TV) character's actions and the consequences of these actions in TV storylines can shape the audience's own behavioral intentions, especially if the audience identifies with that character. The current research examines how storylines depicting positive versus negative consequences of drinking affect youths' drinking intentions, and whether post-narrative intervention messages delivered by story characters alter these influences. Results indicate that a post-narrative intervention can correct drinking intentions shaped by a pro-alcohol storyline, but the effectiveness depends on the source: a peripheral character is more effective than the main character at delivering a corrective message. This research pinpoints the role of identification with the main character as a key driver of stories' influence and a key focus of health intervention efforts to correct these stories' potentially undesirable impact on vulnerable audiences.
\end{abstract}

Keywords: alcohol, media influence, adolescents, source, health promotion, intervention, identification, characters

A robust literature in the fields of communication and media psychology has demonstrated the potential for fictional stories to shape young audiences' real-world beliefs and behaviors not only in a healthy, prosocial manner (i.e., by featuring negative consequences of alcohol consumption), but also in a way that fosters unhealthy behaviors, such as substance use (Russell, Russell, McQuarrie, \& Grube, 2017; Strasburger, Jordan, \& Donnerstein, 2012). Alcohol frequently appears in programming targeting youth audiences, and many TV characters are seen drinking alcohol and experiencing positive consequences as a result (Bergamini, Demidenko, \& Sargent, 2013; Chapoton, Werlen, \& Regnier Denois, 2019; Dal Cin, Worth, Dalton, \& Sargent, 2008; Russell \& Russell, 2009). Public health advocates have expressed concern that pro-alcohol messages in the content of entertainment storylines do not convey realistic consequences of alcohol consumption and may encourage youths to drink (SAMHSA, 2013).

In response, scholars have explored ways to counter potential negative influences of entertainment stories. One approach that may reduce undesired, or reinforce desired, influences of an entertainment narrative is the presentation of an explicit message addressing the story content (Moyer-Gusé, Jain, \& Chung, 2012; Russell et al., 2017). Past research has primarily examined the mere presence (versus absence) of a message from a character on viewers' intentions to model the depicted behavior. However, narratives feature complex worlds that include many characters with varying relationships to the substance in question, raising a surprisingly unexplored question: are some characters more effective sources than others in suppressing undesirable (or enhancing desirable) story-related responses?

This research was designed to investigate two questions related to how story characters affect youths' drinking intentions (Chen, Grube, Bersamin, Waiters, \& Keefe, 2005; Jang, Rimal, \& Cho, 2013). First, we examine whether storylines featuring positive versus negative consequences of drinking differ in their influence depending on whether 
This is an author-produced, peer-reviewed version of this article. The final, definitive version of this document can be found online at Health Communication, published by Routledge. Copyright restrictions may apply. https://doi.org/10.1080/10410236.2020.1733212. The content of this document may vary from the final published version.

they present (or do not present) a character-based post-narrative intervention message. Second, we examine whether there are differences in which character is most effective as the source of the intervention message: the main protagonist versus a peripheral character.

Building on previous research that has documented the potential for post-narrative messages featuring characters as spokespeople to alter the influence of a story on its audience, we consider how distinct story characters, and their actions within the storyline, influence their efficacy as post-narrative messengers. We replicate previous findings that identification with a main character influences the audiences' own intentions to act in a similar way (Caputo \& Rouner, 2011; Moyer-Gusé \& Nabi, 2010), but challenge the assumption that the main character represents the best source of a corrective message. Overall, we contribute to research examining the efficacy of post-narrative messages to correct the influence of stories on young audiences, which also has important practical consequences.

\section{Post-Narrative Messages}

Entertainment narratives may exert a specific persuasion effect, such that they influence their audiences' beliefs, attitudes, and particularly, behavioral intentions in a story-consistent way (Braddock \& Dillard, 2016). Stories allow audiences to learn attitudes toward a target featured in the story (such as drinking alcohol) by observing whether a model is reinforced for the behavior in the storyline (Bandura, 1977; Hinyard \& Kreuter, 2007). For example, a character who experiences positive consequences as a result of binge drinking should enhance viewers' intentions to engage in drinking, whereas a character who suffers as a result of binge drinking should serve as a deterrent.

Post-narrative messages are sometimes appended to the end of entertainment narratives featuring characters consuming risk related substances in order to reinforce the key educational message within a narrative, (Cohen, 2016; Lane, Miller, Brown, \& Vilar, 2013; Moyer-Gusé et al., 2012) or correct for (Adnsager, Austin, \& Pinkleton, 2001; Russell et al., 2017) the narrative's influence on viewers' behavioral intentions. Past research has primarily examined the effects of post-narrative messages featuring the main story character (Moyer-Gusé et al., 2012; Russell et al., 2017), though a peripheral story character (i.e., one who does not engage in the focal behavior) may deliver the message as well. Research examining the influence of these intervention messages suggests that they can be effective in enhancing (if the intervention reinforces the story) or suppressing (if the intervention counters the story) the audience's beliefs and behavior in desired ways (Sangalang, Ophir, \& Cappella, 2019; Singhal \& Rogers, 1999).

In addition to the mere presence (or absence) of the post-narrative intervention, the effect of an intervention on viewers' beliefs and intentions can be understood with reference to the narrative, which demonstrates a particular belief or behavior as desirable or undesirable. Past research on narrative persuasion suggests that, in the absence of a post-narrative intervention, beliefs and behaviors are reinforced in a narrative-consistent manner (Caputo \& Rouner, 2011). In order to replicate these prior narrative persuasion effects, and to provide a benchmark against which to assess the effect of post-narrative interventions, we posit that:

H1: In the context of stories without post-narrative intervention messages, a positive TV story (pro-alcohol) enhances viewers' drinking intentions relative to a negative story (anti-alcohol).

We also expect to replicate previous findings that a post-narrative intervention influences intentions as a function of its positioning relative to the storyline, that is, to enhance acceptance of the storyline message (Cohen, 2016; Lane et al., 2013; Moyer-Gusé et al., 2012), or to reduce acceptance of the storyline message (Adnsager, Austin, \& Pinkleton, 2001; Russell et al., 2017; Sangalang et al., 2019). Participants who view a post-narrative intervention counter to a storyline that conveys positive drinking consequences should report reduced drinking intentions relative to participants who see the story without an intervention. Participants who view a post-narrative intervention that reinforces a storyline that conveys negative drinking consequences should also report reduced drinking intentions relative to participants who view the story without an intervention. Formally:

H2: A post-narrative intervention alters the impact of a TV story featuring alcohol on viewers' intentions to drink: by reducing the impact of a positive story (pro-alcohol) relative to a condition with no post-narrative intervention $(\boldsymbol{H} 2 \boldsymbol{a})$; or reinforcing the impact of a negative TV story (anti-alcohol) relative to a condition with no post-narrative intervention $(\boldsymbol{H} 2 \boldsymbol{b})$. 
This is an author-produced, peer-reviewed version of this article. The final, definitive version of this document can be found online at Health Communication, published by Routledge. Copyright restrictions may apply. https://doi.org/10.1080/10410236.2020.1733212. The content of this document may vary from the final published version.

\section{Post-Narrative Intervention Source and Identification}

Story viewers naturally experience the story world from the perspective of its characters (Cohen, 2001). This process, known as identification, entails vicarious participation in the character's experience, such that viewers adopt characters' goals and experience the characters' emotions as though they were their own (Cohen, 2001). Audiences are more likely to identify with attractive, likeable characters (Brown, 2015) who are similar to themselves (de Graaf, 2014).

Identification is a key mechanism of narrative persuasion (Cohen, 2001; Hoeken, Kolthoff, \& Sanders, 2016). Past research has shown that identification with a character who directly experiences a particular situation or problem influences viewers' beliefs and intentions on the topic in an experience-consistent way (Moyer-Gusé \& Nabi, 2010). Building on this past research we predict that identification with a focal story character in a pro-alcohol storyline should enhance drinking intentions, whereas identification with a focal story character in an anti-drinking storyline should reduce drinking intentions. Note that we do not manipulate the degree to which a character is liked but rather what happens to a likeable character, such that the character experiences positive or negative consequences due to their behavior.

H3: The effect of identification with a key character on drinking intentions will be moderated by storyline valence: when the storyline features positive consequences of drinking, identification will enhance drinking intentions. When the storyline features negative consequences of drinking, identification will reduce drinking intentions.

As previously described, the distinguishing characteristic of a reinforcing versus corrective post-narrative intervention depends on the content of the intervention message (does it support or contradict the central message of the storyline?), and is unrelated to the source of the post-narrative message. Post-narrative interventions typically feature the main character based on the assumption that the audience's connection to a primary character renders them an effective message source (Moyer-Gusé et al., 2012; Russell et al., 2017). However, characters' experiences in stories differ in terms of whether and how their behavior is reinforced: a main character directly experiences the consequences associated with a behavior, whereas a peripheral character may only observe the consequences associated with (the main character's) behavior. Because the post-narrative intervention usually addresses the consequences of actions depicted in the story, and because these consequences may be experienced distinctly by different characters, the audience's acceptance of the post-narrative intervention may be influenced by which character delivers it.

In the context of a reinforcement post-narrative intervention - in which a character reiterates or makes explicit the cause-effect relationship depicted in the story - the source of the intervention may matter less. The audience may be equally likely to accept a message advising against drinking from a main character who experiences negative consequences of drinking as well as from a peripheral character who observed the main character experience negative consequences.

In the context of a corrective post-narrative intervention - in which a character advises the audience not to engage in the behaviors depicted in the narrative -- audience acceptance of the message may depend on the source. When the main character delivers the corrective message, they are directly contradicting the experience that they had in the story. This contradiction may be difficult to process for the audience (Foy \& Gerrig, 2014) whether from a discourse processing perspective or from a social psychology perspective, which could make it hard for the audience to accept that character's admonition not to emulate his actions in a story. When the peripheral character delivers the corrective intervention, they are not contradicting their own experience but rather commenting on their observation of the main character's experience. Despite the growth of research examining the effects of post-narrative interventions, no research to our knowledge examines the effect of post-narrative source on audience acceptance of the message. We thus explore:

RQ1: Do main and peripheral characters differ in their ability to correct drinking intentions following a prodrinking storyline?

This study examines the question of how the valence of a primary TV character's experience associated with alcohol consumption influences viewers' drinking intentions. We also examine how post-narrative messages delivered by different characters (main versus peripheral) correct or reinforce the influence of identification with the primary character on viewers' drinking intentions. 
This is an author-produced, peer-reviewed version of this article. The final, definitive version of this document can be found online at Health Communication, published by Routledge. Copyright restrictions may apply. https://doi.org/10.1080/10410236.2020.1733212. The content of this document may vary from the final published version.

\section{Method}

\section{$\underline{\text { Stimuli Development }}$}

This research was conducted in France as part of a large research program on media influences on youth. Experimental pro- or anti-alcohol TV episodes were professionally produced. The original film was produced in English by a professional university-based film team and was then professionally dubbed to French using lip-sync dubbing. Different versions of the storyline manipulated consequences of the drinking behavior for the main characters and was 18 minutes in length (see Russell et al., 2017).

The story is told from the perspective of a teen, Tom, in a series of events leading up to a beach party where he and his friends drink heavily with other teens. The story emphasized the most relevant expectancies of drinking for the youth audience: the social consequences of the behavior (Jang et al., 2013; Park, Klein, Smith, \& Martell, 2009): the story shows Tom behaving well or badly towards others and directly experiencing positive or negative interpersonal consequences of drinking heavily (acceptance/belonging vs. rejection/alone). This constituted the storyline valence manipulation (alcohol consequences depicted in the story: positive or negative).

\section{$\underline{\text { Stimuli Test }}$}

The story episodes were tested in focus groups. High school students in France viewed pro- or anti-alcohol episodes and gave their opinion. These discussions confirmed that both positive and negative episodes were equally engaging, that the consequences of the positive or the negative storylines were correctly understood, and that the viewers could identify with characters and relate the stories to their own high school experiences. This pre-test thus confirmed the cultural and social relevance of the episodes.

Forty-second video interventions were also produced that featured either Tom, the main character who directly experiences the outcomes, or Katie, a peripheral character, speaking about the consequences of drinking for young people. Per prior research on the most promising approaches for PSAs, messages should emphasize the social outcomes of drinking (Fishbein, Hall-Jamieson, Zimmer, Von Haeften, \& Nabi, 2002). Interventions following the pro-alcohol story began with "what you see on TV is not real. In reality, alcohol changes your behavior in a bad way, it makes you do things you might regret" and interventions following the anti-alcohol story began with "as you saw in the episode..." and the remainder of the message was the same, concluding with "you do not need to drink to have fun and fit in." These messages constituted the post-narrative intervention manipulations.

\section{Participants}

Adolescents were contacted through their parents, who are members of a national commercial research panel in France, to participate in an online survey. A total of 525 parents who reported having legal authority over a child aged 13-17 were briefed about the research. Further screening on the child's age reduced the number of qualifying parents to 504; and 482 of them gave consent for their child to participate. Upon obtaining parental consent, the teen participant received an email invitation and 467 teens assented and accessed the study. Further screening on age led to the removal of 3 who were under 13 and 8 who were above 17.

This study relies on a subset of the overall data (which was part of a broader research program) collected in order to test the current research questions. Of the 353 teens who entered into the study, a total 327 teens completed the 45minute study (57\% males), with all age categories represented equally. The sample was diverse socioeconomically with $50.7 \%$ perceiving their family being as well-off compared as other families, $15.5 \%$ worse-off (below scale midpoint), and $33.8 \%$ better-off.

\section{Procedures}

Participants were randomly assigned to watch either the pro- or the anti-alcohol episode with or without an intervention, according to the 2 (alcohol consequences in the story: positive or negative) X 3 (post-narrative intervention condition: control, Katie-delivered, Tom-delivered) between-subjects design. In the control conditions, participants viewed the positive or negative story but did not view a post-narrative message. Sample numbers averaged 
This is an author-produced, peer-reviewed version of this article. The final, definitive version of this document can be found online at Health Communication, published by Routledge. Copyright restrictions may apply. https://doi.org/10.1080/10410236.2020.1733212. The content of this document may vary from the final published version.

50 in each condition with no differences in age or gender distribution. The 18-minute videos were streamed online, and participants could not forward through them. After viewing the episode, participants completed the self-paced online survey.

Dependent Measure. Measures of current drinking with a separate sample ${ }^{1}$ from the same population indicated that current drinking is low in this age group $(M=.44, S D=.82)$, with $33.1 \%$ indicating no current drinking at all.

Given low prevalence of drinking in this age group, the analyses focus on intentions to drink in the future. Drinking intentions are considered an important indicator in health communication research (Bavin \& Owens, 2016; Park et al., 2009) because they predict subsequent drinking behavior (e.g., Chen et al., 2005; Jang et al., 2013). Participants reported their drinking intentions as follows: "In the next year, how likely it is that you will:" Drink alcohol, Drink several alcoholic drinks in a row, Drink enough to feel drunk (1- not at all likely to 7- very likely). These indicators are commonly used in youth alcohol research (Grube \& Wallack, 1994). and performed reliably $(\alpha=.95, M=2.58$, $S D=1.66)$.

Identification with the Main Character. Participants indicated their identification with the main character on a fiveitem scale anchored by 1- Strongly disagree and 5- Strongly agree (I really identify with (the main character); It could be me instead of him (her) in that story; I can feel what (the main character) is feeling; I was able to get inside his head; I know what (the main character) is going through) (Cohen, 2001; Tal-Or \& Cohen, 2010; $\alpha=.91, M=2.93$, $S D=1.06)$.

Covariates and Story Quality Checks. Age and gender were controlled in analyses, in line with past research demonstrating that males and older adolescents are more likely to drink than females and younger adolescents (Chen et al., 2005). We also controlled for parental strictness, given that parenting styles can influence drinking intention and behavior (Ryan, Jorm, \& Lubman, 2010). We measured participants" perception of the realism of the story ("What happened to Tom was realistic" on 1 = "not at all" to 7 = "a great deal" scales) and attitude towards the story ("Overall, I enjoyed watching the episode" on 1 = "not at all" to 5 "a great deal" scales) as confound checks

\section{Results}

\section{Data and Story Quality Check}

We removed participants who spent more than 3 standard deviations above the median time to view the video (i.e., suggesting inattentiveness; $\mathrm{n}=9$ ) or who did not view the full video due to technical malfunction $(\mathrm{n}=2)$, yielding a final sample size of 316. There were no differences in the perceived realism (overall $M=6.26, S D=2.14, F s<1.32$, $p s>.28$ ) or attitude towards the episode (overall $M=3.71, S D=1.12, F s<1.81$, ps $>.17$ ) as a function of the manipulations.

\section{Drinking Intentions}

We analyzed drinking intentions with a 2 (story valence: positive, negative) x 3 (Post-narrative intervention: control, Tom-delivered, Katie-delivered) ANCOVA, controlling for gender and age. This analysis revealed a significant interaction as reported in table $1(F(1,307)=3.00, p=.05)$ and depicted in Figure 1. No other effects were significant. A planned contrast to compare the influence of the positive and negative storyline control conditions (i.e., those without post-narrative messages) on drinking intentions shows support for H1: participants who viewed the positive storyline control condition report greater intentions to drink in the future $(M=2.88, S D=1.71)$ than participants in the negative storyline control condition $(M=2.32, S D=1.57, F(1,307)=4.04, p<.05)$.

To test RQ1, we examined the effects of the post-narrative interventions on drinking intentions relative to the control conditions through a series of planned contrasts. In the positive storyline condition ${ }^{2}$, the post-narrative intervention featuring the main character from the story did not differ from the control $(F(1,312)=.19, p=.66)$. However, the post-narrative intervention featuring a peripheral character from the story did suppress drinking intentions relative to the control $\left(F(1,307)=3.94, p<.05 ; M_{\text {peripheral character }}=2.12, S D=1.38 ; M_{\text {control }}=2.88, S D=1.71\right)$, and relative to the

\footnotetext{
${ }^{1}$ Participants reported current alcohol consumption by indicating how often they currently drink each of each of seven types of alcohol: beer, wine, strong alcohols, pre-mixes, cider, champagne, other alcohol. Answers to these items were coded as never $=0$; rarely $=1$; about once a month $=2$; about once a week $=3$; daily $=4$ and were averaged $(\alpha=.89)$ to create a current drinking indicator.

${ }^{2}$ There were no effects of post-narrative intervention source on drinking intention in the negative storyline condition.
} 
This is an author-produced, peer-reviewed version of this article. The final, definitive version of this document can be found online at Health Communication, published by Routledge. Copyright restrictions may apply. https://doi.org/10.1080/10410236.2020.1733212. The content of this document may vary from the final published version.

condition featuring the main character $(F(1,307)=6.17, p<.05, M=2.77, S D=1.59)$. Thus, only a post-narrative intervention delivered by a peripheral character was able to correct the influence of a positive drinking-related storyline on viewers' drinking intentions.

We tested $\mathrm{H} 2$ with a 2 (story valence: positive, negative) x 2 (post-narrative intervention: present, absent) ANCOVA on drinking intentions, controlling for gender and age. No effects are significant $(\mathrm{Fs}<2.14)$.

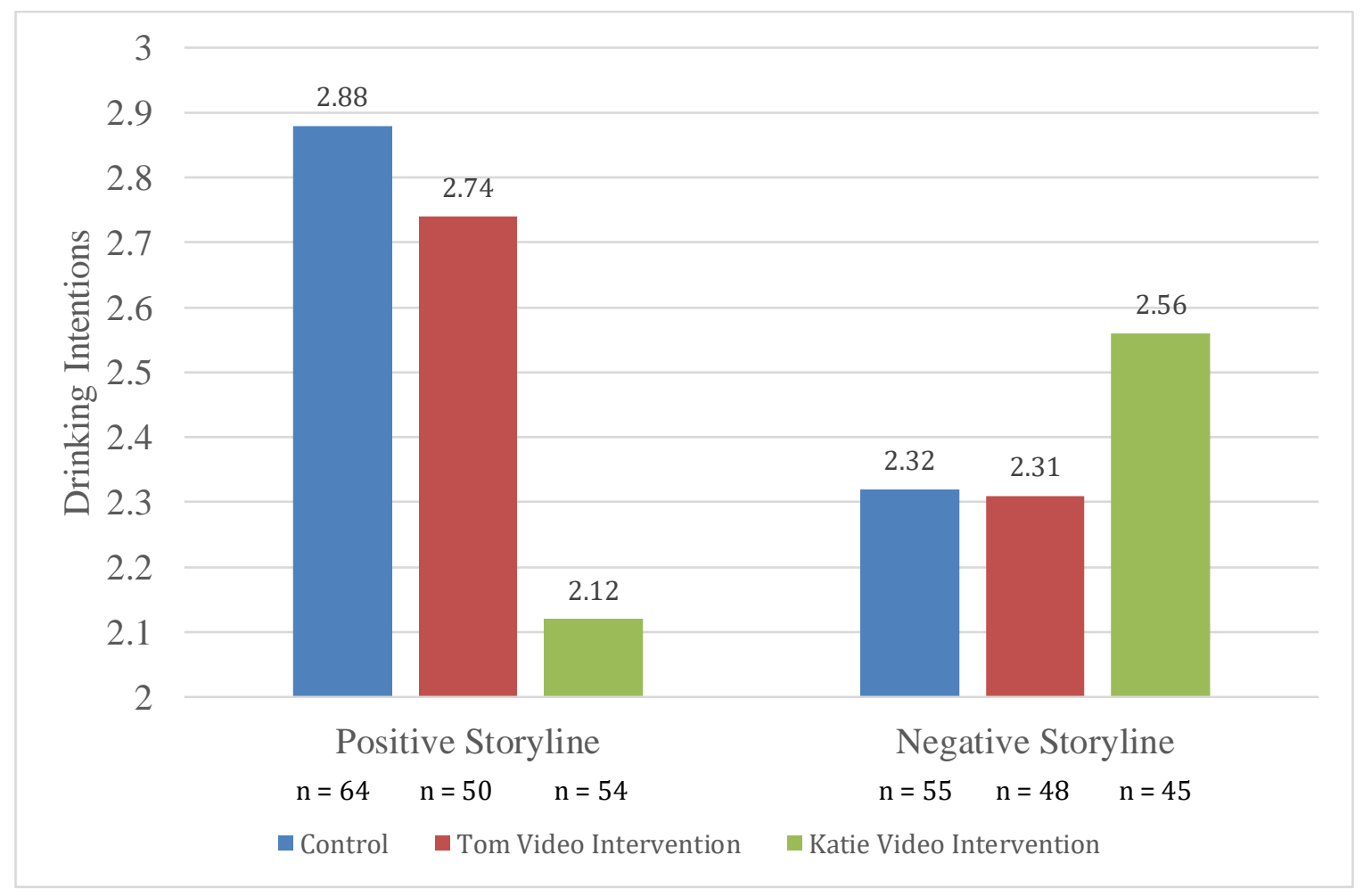

Figure 1: Interaction of storyline valence and character intervention on viewers' drinking intentions.

\section{$\underline{\text { Identification with the Main Character as a Mechanism of Influence. }}$}

We next explored the role of identification with story characters, by assessing whether identification ${ }^{3}$ with a key story character influences drinking intentions. We first examined whether, as past research would predict, identification with the main story character influenced drinking intentions in a manner consistent with the storyline: that is, whether identification with a focal story character in a pro-alcohol storyline enhances drinking intentions, whereas identification with a focal story character in an anti-drinking storyline reduces intentions (H3).

Focusing on the control conditions (those without post-narrative interventions), we regressed drinking intentions onto identification with Tom, story valence, and their interaction, controlling for age, gender, and parental strictness. A main effect of identification emerged such at identification with Tom enhanced drinking intentions $(b=.34, t=2.09$, $p<.05)$. Story valence exerted a marginal effect, such that the positive storyline enhanced drinking intentions relative to the negative storyline $(b=.52, t=1.74, p=.08)$. No other effects, namely the interaction, were significant. Thus, the effects of identification did not differ depending on the valence of the storyline.

\footnotetext{
${ }^{3}$ To check whether the manipulations evoked differences in identification with the focal character, we conducted a 2 (story valence: positive, negative) x 3 (Post-narrative intervention: control, Tom-delivered, Katie-delivered) ANCOVA on identification with Tom, controlling for gender and age. No effects were significant $(F s<2.92)$, with the exception of gender $(F(1,312)=5.89, p=.02)$, such that males were more likely to identify with Tom.
} 
This is an author-produced, peer-reviewed version of this article. The final, definitive version of this document can be found online at Health Communication, published by Routledge. Copyright restrictions may apply. https://doi.org/10.1080/10410236.2020.1733212. The content of this document may vary from the final published version.

Given the results of RQ1, we conducted exploratory analyses to examine whether the influence of identification with Tom on drinking intentions varied depending on the post-narrative intervention. We focused on the positive storyline conditions $^{4}$, and created dummy variables to denote the post-narrative intervention conditions, treating the Katiedelivered intervention condition as the reference group (as differences in drinking intentions emerged in this condition): the first dummy variable coded $1=$ no intervention; $0=$ Katie intervention enabled comparison between the no intervention condition and the intervention featuring Katie and the second dummy variable coded $1=$ Tom; $0=$ Katie enabled comparison between the Tom and Katie delivered post-narrative interventions. Regression of drinking intentions onto identification with Tom, the dummy condition variables, and the two-way interactions between identification and the dummy conditions, controlling for age, gender, and parental strictness reveals a significant effect of the control dummy (relative to Katie-delivered intervention; consistent with the ANCOVA results) qualified by a 2 -way interaction between this dummy and identification with Tom; see Table 2. Figure 2 maps out this interaction and shows that identification with Tom exerted a strong, positive effect on drinking intentions when he delivered the post-narrative intervention $(b=.62, t=3.13, p<.001)$, but not when Katie delivered it $(b=.08, t=.41, p<.68)$.

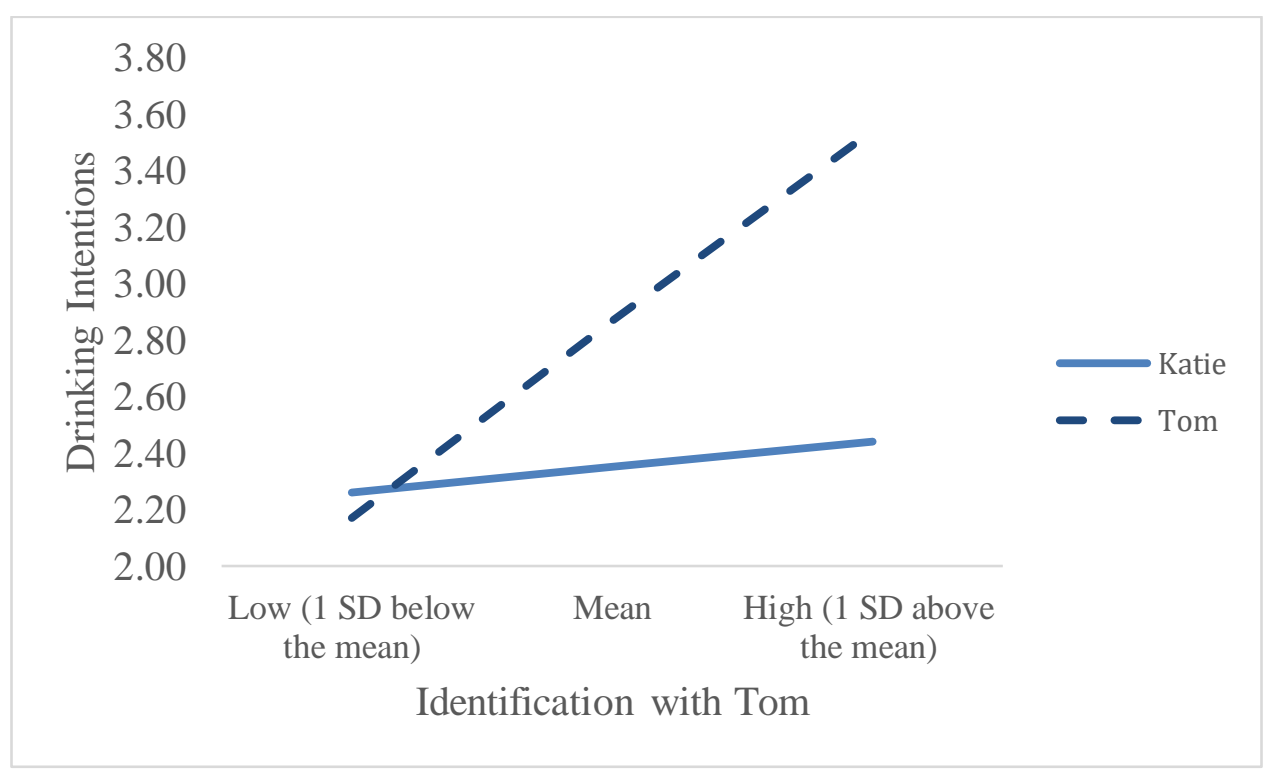

Figure 2: Relationship of identification with Tom and drinking intentions as a function of the post-narrative intervention source (in the positive storyline conditions)

\section{Discussion}

\section{Theoretical Implications}

The current research presents novel insights that build upon past findings. First, the findings are consistent with a large body of evidence supporting the subtle, persuasive effects of stories, which indicate the need for a corrective intervention (Braddock \& Dillard, 2016): a positive alcohol story (without a corrective message) enhanced viewers' drinking intentions relative to a story featuring negative consequences (supporting H1). This pattern reinforces the concerns of public health advocates who have called for both closer monitoring of the content of media portrayals and corrective action to palliate their detrimental impact (Bergamini et al., 2013).

Strictly speaking, we did not replicate past work demonstrating that the presentation of a post-narrative corrective message can reduce the impact of a (pro-alcohol) story, or reinforce the impact of an (anti-alcohol) message; there was no main effect of post-narrative message on drinking intention (H2) (Russell et al., 2017; Sangalang et al., 2019). However, analyses exploring the full design and accounting for the effect of which character delivered the message (to explore RQ1) show that messengers are not all equally effective as intervention sources. The character who

\footnotetext{
${ }^{4}$ Analyses including the negative conditions (and each of the two- and three-way interactions with valence) showed that valence was not significant. Differences in drinking intentions emerged only in the positive condition. We thus focus the analysis on the positive conditions in the interest of ease of presentation.
} 
This is an author-produced, peer-reviewed version of this article. The final, definitive version of this document can be found online at Health Communication, published by Routledge. Copyright restrictions may apply. https://doi.org/10.1080/10410236.2020.1733212. The content of this document may vary from the final published version.

experienced positive consequences from drinking (Tom) was less effective as a corrective messenger than one who did not personally experience positive outcomes from alcohol consumption (Katie). Collectively, these findings suggest that a more nuanced approach to implementing post-narrative messages is warranted. While prior research points to the presence of a post-narrative message as an effective way to attenuate the effects of a positive-drinking storyline on viewers, our work suggests that it can be, depending on who delivers the message.

Perhaps surprisingly, in contrast with past research (Cohen, 2016; Lane et al., 2013; Moyer-Gusé et al., 2012), the post-narrative messages did not reinforce the effectiveness of the negative consequences of drinking depicted in the storyline, regardless of the source. This could be explained by valence asymmetries and the effects of punishment versus reinforcement on observational learning, and persuasive influence of contradictory versus consistent messages. For example, storylines may exert effects on behavior through observational learning (Bandura, 1977), but also through aspirational intentions (i.e. wanting to be like Tom, regardless of the consequences of his behavior).

The current research also differs from past work in methodological ways. Sangalang, Ophir, and Cappella (2019), for example, found that a corrective message presented by the main character was effective in reducing undesirable attitudes and intentions towards e-cigarettes. A key difference between our work and theirs is that, in Sangalang et al. (2019), the main character did not use the described substance. Relatedly, Moyer- Gusé et al. (2012), found that participants were less favorable towards drinking and driving following an anti-drinking storyline with an explicit appeal, relative to exposure to the story alone. The differing results may be explained by several differences between their study and the present: the population examined (college students versus adolescents), the source of the appeal (a well-known actress versus unknown actors), the content of the appeal (a reminder of the dangers of drunk driving versus a reminder that what is shown on TV is not real), the target context itself (drinking and driving versus drinking in general), and the dependent measures (attitudes towards drunk driving versus personal drinking intentions).

Further, the prediction that the influence of identification with the main story character on drinking intentions differed depending on story condition (H3) was not supported. Cohen (2001) suggests that people are influenced by identification with story characters because they vicariously strive for the characters' goals and experience the subsequent rewards and punishments. In contrast, we find that identification with the main character exerted a positive influence on drinking intentions, regardless of whether the consequences he experienced in the story were negative. Given that TV stories contain many sub arcs within the broader story arc, many types of rewards are displayed, and some, such as hedonic rewards, may weigh more heavily on teens' intentions relative to punishments. For instance, the negative story, where Tom ultimately experienced negative consequences in the macro structure, depicted Tom having fun when drinking. Thus, it is possible that identification with Tom enhanced drinking intentions, irrespective of storyline valence through simple modeling; as a likeable character, participants may have been more likely to act like Tom, irrespective of the consequences of his behavior.

This possibility is substantiated by the finding that the most corrective post-narrative intervention appeared to block the identification driver. When Katie was the source of the counter-message, the relationship between identification with Tom and drinking intentions became nonsignificant. This finding points to a promising direction for future efforts to curtail the effects of stories on undesirable behavior: rather than counterarguing against the depicted cause-effect relationships in the story, intervention approaches may prove more effective if they weaken the effect of connection with key story characters on the outcomes of interest.

On a broader level, the evidence presented here contributes to the literature on correcting misinformation: the presentation of a new story correcting a misinformation is more effective to update peoples' mental models of an event than asserting that the information is false (Lewandowsky, Ecker, Seifert, Schwarz, \& Cook, 2012). As asserted by Seifert (2002), a negation does not address the initial evaluation of the information as true and relevant. The current results may be interpreted in light of this work: a correction delivered by a character who experienced positive consequences from drinking in the storyline and does not explain why the character is, in effect, presenting a direct negation. A correction delivered by a peripheral character may be viewed as less of a direct negation and may effectively prompt consideration of what happened in the story. As aforementioned, the identification analyses showed that the peripheral character appeared to deactivate the effects of identification with the main character on drinking intentions. 
This is an author-produced, peer-reviewed version of this article. The final, definitive version of this document can be found online at Health Communication, published by Routledge. Copyright restrictions may apply. https://doi.org/10.1080/10410236.2020.1733212. The content of this document may vary from the final published version.

\section{Practical Implications}

That a brief character-delivered message can significantly reduce the influence of a pro- alcohol storyline on viewers is promising in terms of media interventions. From a prevention standpoint, this suggests a straightforward approach to effectively correct media-based portrayals of substance use. In the age of streaming media and viewing-on-demand, this is particularly easy to operationalize. The fact that the more effective messenger was not the primary character opens many (and likely less costly) options for character-delivered corrections.

An equally important finding is that stories depicting negative consequences of drinking do not need follow up interventions, since those did not have any apparent impact on drinking-related attitudes and intentions. This finding is a reminder not to overuse public health interventions when the context in which they appear already displays substance use negatively, especially with a generally skeptical youth audience (Fishbein et al., 2002; Pechmann \& Wang, 2010). However, the finding that identification with the main character did enhance drinking intentions regardless of the ultimate valence of the drinking consequences, highlights the need to carefully consider how all plot points in a story contribute to the viewers' overall impression, rather than the ending alone.

\section{$\underline{\text { Limitations and Future Directions }}$}

The current study relied on a single exposure to an entire episode and viewing conditions only approximated the real world. Replications across other substance contexts and audiences are warranted, as well as extensions with multiple exposures. Further, while the study was able to generate and detect differences in the degree of identification with the main character after a single episode, it is recognized that identification with characters in a TV series develops over time, and that exposure to multiple episodes would further increase levels of identification and augment their downstream influences. Future research should also assess other ways in which alcohol storylines and post-narrative interventions may affect their audience, for instance by affecting perceived norms about alcohol consumption, which indirectly drive media influences on youth (Elmore, Scull, \& Kupersmidt, 2017).

\section{Conclusion}

This work highlights the complex influence of characters as message sources in the context of media depicting adolescent alcohol consumption. A post-episode video intervention featuring a peripheral character (versus the main character) reduces the influence of a pro-alcohol storyline because this intervention suppresses the influence of identification with the character who drinks on viewers' intention to behave in the same manner.

\section{References}

Adnsager, J.L., Austin, E.W., \& Pinkleton, B.E. (2001). Questioning the value of realism: Young adults' processing of messages in alcohol-related public service announcements and advertising. Journal of Communication, 51, 121-142. doi: 10.1111/j.1460-2466.2001.tb02875.x

Bandura, A. (1977). Self-efficacy: Toward a unifying theory of behavior change. Psychology Review, 84, 191-215. doi: 10.1016/0146-6402(78)90002-4

Bavin, L.M., \& Owens, R.G. (2016). Impact of an alcohol poisoning storyline in a fictional television program: An experimental study with a live-to-air stimulus. Health Communication, 31, 1258-1265. doi: 10.1080/10410236.2015.1055537

Bergamini, E., Demidenko, E., \& Sargent, J.D. (2013). Trends in tobacco and alcohol brand placements in popular US movies, 1996 through 2009. JAMA Pediatrics, 167, 634-639. doi: 10.1001/jamapediatrics.2013.393

Braddock, K., \& Dillard, J.P. (2016). Meta-analytic evidence for the persuasive effect of narratives on beliefs, attitudes, intentions, and behaviors. Communication Monographs, 83, 446-467. doi: $10.1080 / 03637751.2015 .112855$

Brown, W.J. (2015). Examining four processes of audience involvement with media personae: Transportation, parasocial interaction, identification, and worship. Communication Theory, 25, 259-283. doi: $10.1111 /$ comt. 12053

Caputo, N.M., \& Rouner, D. (2011). Narrative processing of entertainment media and mental illness stigma. Health Communication, 26, 595-604. doi: 10.1080/10410236.2011.560787

Chapoton, B., Werlen, A., \& Regnier Denois, V. (2019) Alcohol in TV series popular with teens: a content analysis of TV series in France 22 years after a restrictive law. European Journal of Public Health, ckz163, doi: 10.1093/eurpub/ckz163 
This is an author-produced, peer-reviewed version of this article. The final, definitive version of this document can be found online at Health Communication, published by Routledge. Copyright restrictions may apply. https://doi.org/10.1080/10410236.2020.1733212. The content of this document may vary from the final published version.

Chen, M.J., Grube, J.W., Bersamin, M., Waiters, E., \& Keefe, D.B. (2005). Alcohol advertising: What makes it attractive to youth? Journal of Health Communication, 10, 553-565. doi: 10.1080/10810730500228904

Cohen, J. (2001). Defining identification: A theoretical look at the identification of audiences with media characters. Mass Communication \& Society, 4, 245-264. doi: 10.1207/S15327825MCS0403_01

Cohen, E.L. (2016). Exploring subtext processing in narrative persuasion: The role of eudaimonic entertainment-use motivation and a supplemental conclusion scene. Communication Quarterly, 64, 273-297. doi: 10.1080/01463373.2015.1103287

Dal Cin, S., Worth, K.A., Dalton, M.A., \& Sargent, J.D. (2008). Youth exposure to alcohol use and brand appearances in popular contemporary movies. Addiction, 103, 1925-1932. doi: 10.1111/j.13600443.2008.02304.x

De Graaf, A. (2014). The effectiveness of adaptation of the protagonist in narrative impact: Similarity influences health beliefs through self-referencing. Human Communication Research, 40, 73-90. doi: 10.1111/hcre.12015

Elmore, K.C., Scull, T.M., \& Kupersmidt, J.B. (2017). Media as a "super peer": How adolescents interpret media messages predicts their perception of alcohol and tobacco use norms. Journal of Youth and Adolescence, 46, 376-387. doi: 10.1007/s10964-016-0609-9

Fishbein, M., Hall-Jamieson, K., Zimmer, E., Von Haeften, I., \& Nabi, R. (2002). Avoiding the boomerang: Testing the relative effectiveness of antidrug public service announcements before a national campaign. American Journal of Public Health, 92, 238-245. doi: 10.2105/AJPH.92.2.238

Foy, J.E., \& Gerrig, R.J. (2014). Readers' responses when characters act on completed goals: Impact of characters' mental states and readers' task focus. Discourse Processes, 51, 312-332. doi: $10.1080 / 0163853 X .2013 .867800$

Grube, J. \& Wallack, L. (1994). Television beer advertising and drinking knowledge, beliefs, and intentions among schoolchildren. American Journal of Public Health, 84, 254-259. doi: 10.2105/ajph.84.2.254

Hinyard, L.J., \& Kreuter, M.W. (2007). Using narrative communication as a tool for health behavior change: A conceptual, theoretical, and empirical overview. Health Education \& Behavior, 34, 777-792. doi: $10.1177 / 1090198106291963$

Hoeken, H., Kolthoff, M., \& Sanders, J. (2016). Story perspective and character similarity as drivers of identification and narrative persuasion. Human Communication Research, 42, 292-311. doi: 10.1111/hcre. 12076

Jang, S.A., Rimal, R.N., \& Cho, N. (2013). Normative influences and alcohol consumption: The role of drinking refusal self-efficacy. Health Communication, 28, 443-451. doi: 10.1080/10410236.2012.691455

Lane, R., Miller, A. N., Brown, C., \& Vilar, N. (2013). An examination of the narrative persuasion with epilogue through the lens of the elaboration likelihood model. Communication Quarterly, 61, 431-445. doi: 10.1080/01463373.2013.799510

Lewandowsky, S., Ecker, U. K. H. Seifert, C. M., Schwarz, N., \& Cook,J. (2012). Misinformation and its correction: Continued influence and successful debiasing. Psychological Science in the Public Interest, 13, 106-131. doi: $10.1177 / 1529100612451018$

Moyer-Gusé, E., Jain, P., \& Chung, A. H. (2012). Reinforcement or reactance? Examining the effect of an explicit persuasive appeal following an entertainment-education narrative. Journal of Communication, 62, 10101027. doi: $10.1111 / \mathrm{j} .1460-2466.2012 .01680 . x$

Moyer-Gusé, E., \& Nabi, R.L. (2010). Explaining the effects of narrative in an entertainment television program: Overcoming resistance to persuasion. Human Communication Research, 36, 26-52. doi: 10.1111/j.14682958.2009.01367.x

Park, H.S., Klein, K.A., Smith, S., \& Martell, D. (2009). Separating subjective norms, university descriptive and injunctive norms, and US descriptive and injunctive norms for drinking behavior intentions. Health Communication, 24, 746-751. doi: 10.1080/10410230903265912

Pechmann, C., \& Wang, L. (2010). Effects of indirectly and directly competing reference group messages and persuasion knowledge: Implications for educational placements. Journal of Marketing Research, 47, 134145. doi: 10.1509/jmkr.47.1.134

Russell, C.A., \& Russell, D.W. (2009). Alcohol messages in prime-time television series. Journal of Consumer Affairs, 43, 108-128. doi: 10.1111/j.1745-6606.2008.01129.x

Russell, C.A., Russell, D.W., McQuarrie, E., \& Grube, J. (2017). Alcohol storylines in television episodes: The preventive effect of countering epilogues. Journal of Health Communication, 22, 657-665. doi: $10.1080 / 10810730.2017 .1341564$ 
This is an author-produced, peer-reviewed version of this article. The final, definitive version of this document can be found online at Health Communication, published by Routledge. Copyright restrictions may apply. https://doi.org/10.1080/10410236.2020.1733212. The content of this document may vary from the final published version.

Ryan, S.M., Jorm, A.F., \& Lubman, D.I. (2010). Parenting factors associated with reduced adolescent alcohol use: A systematic review of longitudinal studies. Australian \& New Zealand Journal of Psychiatry, 44, 774-783. doi: 10.1080/00048674.2010.501759

Sangalang, A., Ophir, Y., \& Cappella, J.N. (2019). The potential for narrative correctives to combat misinformation. Journal of Communication, 69, 298-319. doi: 10.1093/joc/jqz014

Singhal, A., \& Rogers, E. M. (1999). Entertainment-education: A communication strategy for social change. Mahwah, NJ: Erlbaum.

Seifert, C.M. (2002). The continued influence of misinformation in memory: What makes a correction effective? In Psychology of Learning and Motivation (Vol. 41, pp. 265-292). Academic Press. doi: 10.1016/S00797421(02)80009-3

Strasburger, V.C., Jordan, A.B., \& Donnerstein, E. (2012). Children, adolescents, and the media: Health effects. Pediatric Clinics of North America, 59, 533-587. doi: 10.1016/j.pcl.2012.03.025

Substance Abuse and Mental Health Services Administration (SAMHSA). (2013). Results from the 2012 national survey on drug use and health: Summary of national findings. NSDUH Series H-46. Rockville, MD: Substance Abuse and Mental Health Services Administration.

Tal-Or, N., \& Cohen, J. (2010). Understanding audience involvement: Conceptualizing and manipulating identification and transportation. Poetics, 38, 402-418. doi: 10.1016/j.poetic.2010.05.004

Table 1

ANCOVA on Drinking Intentions

\begin{tabular}{llll}
\hline Source & df & $F$ & Sig \\
\hline Corrected Model & 8 & 1.41 & 0.19 \\
Intercept & 1 & 72.91 & 0.00 \\
Gender & 1 & 1.18 & 0.28 \\
Age & 1 & 1.07 & 0.30 \\
Parental Strictness & 1 & 0.03 & 0.88 \\
Episode Valence & 1 & 1.42 & 0.23 \\
Post-narrative Intervention & 2 & 0.96 & 0.39 \\
Valence x Post-narrative Intervention & 2 & 3.00 & 0.05
\end{tabular}


This is an author-produced, peer-reviewed version of this article. The final, definitive version of this document can be found online at Health Communication, published by Routledge. Copyright restrictions may apply. https://doi.org/10.1080/10410236.2020.1733212. The content of this document may vary from the final published version.

Table 2

Drinking Intentions Regressed onto Identification with the Main Character in the Positive Storyline Condition

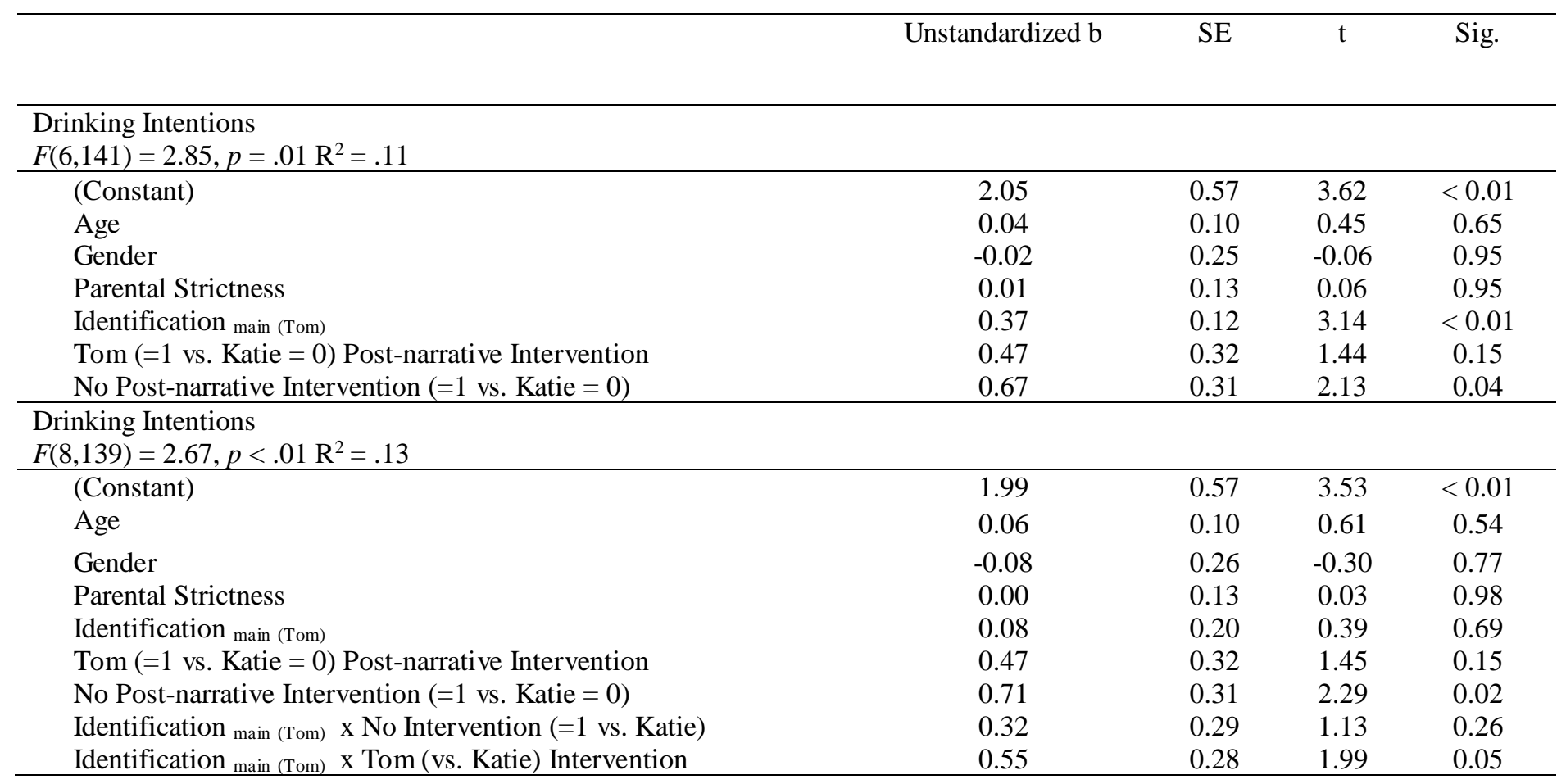

